\title{
The Neurobehavioural Abnormalities in Parkinson's Disease and their Relationship to Psychomotor Retardation and Obsessional Compulsive Disorders
}

\author{
A. J. LEES \\ The National Hospitals for Nervous Diseases, Queen Square, London, WC1, UK
}

Claims that dementia occurs in Parkinson's disease stretch back for over a century, but this still remains a contentious issue. The evidence that an Alzheimer-type dementia occurs more frequently than one would expect by the chance association of two common disorders remains unproven (Brown and Marsden, 1984; Lees, 1984). Parkinson's disease may also be confused clinically with cortical Lewy body disease (Gibb et al., 1987), HallervordenSpatz syndrome (Jankovic et al., 1985) and cortico-basal degeneration (Rebeiz et al., 1968), disorders in which Alzheimer-type dementia may occur. In 1974 the term subcortical dementia was introduced which included cognitive slowing, forgetfulness and personality changes including depression. Equally important negative findings are the absence of dysphasia, dyspraxia and agnosia (Albert et al., 1974). Generally this is a milder disorder than Alzhemier-type dementia and probably does not fulfil the DSM III criteria for dementia. Subcortical dementia subsumes the old term bradyphrenia which was coined by Naville in 1922 to describe the psychological impairment of many patients with postencephalitic Parkinson's syndrome characterized by slowness of thinking, apathy, poor attention and difficulty in decision making. Together with Huntington's disease and the Steele-Richardson-Olszewski syndrome, Parkinson's disease is considered one of the best examples of a degenerative neurological condition causing subcortical dementia.

\section{The neuropsychological abnormalities found in Parkinson's disease}

Individuals with Parkinson's disease often complain of mild forgetfulness, loss of interest, flatness of emotion and a slight reduction in spontaneity. They may also become socially withdrawn, lose confidence and drive and complain that trivialities engender intense anxiety. One characteristic feature is that the patient is often able to raise his performance temporarily when he is motivated to do so. This may explain why it has been extremely difficult to demonstrate consistent impairments on neuropsychological testing. Nevertheless a few subtle non-specific cognitive abnormalities have been found. 


\section{Diffculties in initiating, completing and switching cognitive sets}

Barbeau (1973) first drew attention to the difficulty patients with Parkinson's disease have with shifting sets. "Akinetic patients appear bradypsychic, although most usual tests of intelligence are within normal limits. However, patients have a defect in the strategy of learning with difficulties in shifting to new grouping on the sorting test of Goldstein". The most popular psychological test used to investigate this difficulty has been the Wisconsin card sorting test which requires the subject to impose a strategy on ambiguous or incomplete material (Berg, 1948). The subject is required to sort 2 sets of 64 response cards comprising all possible combinations of colour, shape and number attributes. The subject is instructed to place each card below 1 of 4 unique stimulus cards and after each response is told whether the response was correct. After each 10 appropriate responses the category changes without warning according to an internal sequence. The number of cards required to achieve the first successful sorting, the number of correct categories recorded and the number of errors (perseverative or non-perseverative) are noted. Because of difficulties in carrying out the test in normal elderly subjects and because of certain ambiguities, a simplified version has been used by some investigators using a total pack of 2 sub-sets of 24 response cards (Nelson, 1976). Reported results using the Wisconsin card sorting test are summarized in Table 1. Although all the studies have demonstrated abnormalities these have differed to some degree from one study to the next. For example, Taylor and colleagues (1986) have emphasized the difficulty in achieving the first cognitive category, whereas Lees and Smith (1983) noted difficulty in switching sets with an increased number of perseverative errors. Some patients were able to verbalise the correct response but failed to execute the correct strategy as if their hands would not do what they were being told to do. Flowers and Robertson (1985) devised a similar but simpler test to distinguish between impairment

TABLE 1. The Results on the Wisconsin Card Sorting Test in Parkinson's Disease

\begin{tabular}{|c|c|c|c|c|c|c|}
\hline \multirow[b]{2}{*}{ Author(s) } & \multirow[b]{2}{*}{$\begin{array}{l}\text { No. of } \\
\text { patients }\end{array}$} & \multirow[b]{2}{*}{$\begin{array}{l}\text { Mean } \\
\text { age } \\
(y r s)\end{array}$} & \multirow[b]{2}{*}{$\begin{array}{c}\text { No. } \\
\text { treated }\end{array}$} & \multirow[b]{2}{*}{$\begin{array}{c}\text { No. } \\
\text { untreated }\end{array}$} & \multicolumn{2}{|c|}{ Wisconsin results } \\
\hline & & & & & $\begin{array}{c}\text { No. of } \\
\text { categories }\end{array}$ & $\begin{array}{c}\text { No. of } \\
\text { perservative } \\
\text { errors }\end{array}$ \\
\hline Bowel et al. (1975) & 71 & 63 & 53 & 18 & $*$ & n.s. \\
\hline + Lees and Smith (1983) & 30 & 59 & 0 & 30 & $*$ & $*$ \\
\hline Taylor et al. (1986) & 40 & 61 & 28 & 12 & $*$ & n.s. \\
\hline Starkstein et al. (1987) & 18 & 57 & 18 & 0 & $*$ & n.s. \\
\hline Gotham et al. (1988) & 16 & 60 & 16 & 0 & $*$ & $*$ \\
\hline Canavan et al. (1988) & 19 & 58 & 1 & 18 & n.s. & $*$ \\
\hline
\end{tabular}

$+=$ Nelson modification of Wisconsin Test

$*=$ significant reduction in categories completed or increase in perseverative errors 
in the understanding of concepts on the one hand and difficulty in the control of applying concepts on the other. On this Odd Man Out test, subjects were asked to indicate which of a set of letters or shapes were different from the others in 2 series of cards using 2 rules of classification on successive trials. The pattern of error found in 49 treated patients (mean age $64 \pm 9 \cdot 2$, duration of disease 1-33 years) suggests that the difficulty in the switching tests arose from an instability of cognitive set rather than loss of reasoning, perseveration or increased distractibility. It is possible that patients with Parkinson's disease may be impaired only on tasks where they have to rely on internal control for regulation of behaviour and are relatively unimpaired on tasks where external cues are available. The type of abnormality reported in these studies is similar to that often seen in elderly normal controls and patients with frontal lobe damage. Sandson and Albert (1987) have recently proposed a new classification of perseverative behaviour defining 3 distinct types. Most of the reported perseverative abnormalities seen in patients on the Wisconsin card sorting test would fit best for their "stuck-in-set" type which they attribute to a disorder of executive function and integration of multiple outputs. Lees and Smith (1983) however, also reported recurrent perseveration with repetition of a previous correct letter response on the Benton word fluency test, a disorder which according to Sandson and Albert is more commonly seen in patients with dysphasic difficulties.

\section{A slowing of ideation, "time to make one's mind up", or central information processing time}

Mettler (1955) defined the subtle neuropsychological impairments one finds in Parkinson's disease as follows: "Because of the difficulty in disentangling slowness of motor response from slowness of thought almost a hundred years of debate have failed to resolve the notion that bradyphrenia might occur in Parkinson's disease". Naville (1922) devised a series of tests in which the motor element remained the same but the intellectual difficulty varied and he was able to show a slowing of intellectual function in patients with Parkinson's disease compared with controls. Shortly afterwards, however, Worster-Drought and Hardcastle (1924) found that while psychomotor reaction time was lengthened in patients with postencephalitic Parkinson's syndrome, "cerebration time" was not appreciably affected. Wilson (1955) attributed mental slowing in Parkinson's disease to an associated depression and did not consider that bradyphrenia should be regarded as an integral component of the clinical picture of Parkinson's disease. Different experimental studies of reaction times and motor performance have shown that a central "slowing of movement" may be involved as well as more peripheral components (Brumlik and Boshes, 1966; Everts et al., 1981). This central motor disorder might well contribute to what others have described as bradyphrenia and different perceptions of central slowing as a motor or mental phenomenon might explain much of the conflict within the literature. The selection of patients for study particularly with respect to the 
presence or absence of associated depression may also be important; this has its own intrinsic slowing of movement and abnormalities of cognitive function.

Wilson and colleagues (1980) have measured the speed and accuracy of short term memory scanning using the Sternberger paradigm and found that the scanning speed was deceased in a sub-group of elderly Parkinsonian patients. Hanach and colleagues (1982) found a significant age-independent negative correlation between the score on a digit symbol test and the latency of the P-300 component of an auditory event-related potential; there was a significantly increased latency of the P-300 in the patients compared with normal controls which correlated well with the degree of psychomotor slowing. In contrast, Rafal and colleagues (1984) studied 10 patients with Parkinson's disease before and after L-dopa treatment, or in on and off periods during therapy, and were unable to detect a primary cognitive component to the slowing of memory scanning and orientation.

Dr Daniel Rogers and I studied 30 newly diagnosed patients with Parkinson's disease, 30 patients with primary depressive illness and 30 agematched controls using 2 computerised psychological tests differing in cognitive complexity (choice reaction time and digit symbol substitution task) but with the same motor response (pressing a keyboard) in an attempt to determine whether slowing of central processing time occurs in Parkinson's disease and depression. We were able to demonstrate significant "cognitive and psychomotor slowing" in the patients with Parkinson's disease which was related to the presence of structural brain disorder (minor CT brain scan abnormalities, WAIS VIQ:PIQ discrepancies) and to the severity of associated affective impairment (5 to 8 items on the Spitzer research diagnostic criteria for depression and Hamilton depression score). With treatment for a mean period of 9 months with dopaminergic drugs, surprisingly no overall significant change in motor or affective status occurred in the 12 patients randomly selected for re-study, but changes in the time to complete the digit test correlated with individual changes in depression rating. Both "cognitive" and psychomotor slowing also occurred in the group of depressed patients and here it correlated with the presence of motor impairment (as assessed by the Webster Scale used for assessing Parkinsonian symptoms). In contrast the 12 depressed patients selected for re-testing showed significant improvement in cognitive slowing following treatment with antidepressants (Rogers et al., 1987). These results raise the possibility that bradyphrenia in Parkinson's disease and psychomotor retardation in depression may be closely related. They may indeed be identical phenomena mediated by similar underlying chemical disturbances within the brain.

\section{The relationship between the neuropsychological abnormalities in depression and those found in Parkinson's disease}

Depression occurs in about $50 \%$ of patients with Parkinson's disease, which is probably about double the figure quoted for most other chronic disabling 
physical illness. About $20 \%$ of patients with Parkinson's disease have had at least one marked depressive episode before the onset of motor symptoms (Shaw et al., 1980). This may reflect the first manifestation of Parkinson's disease rather than suggesting any linked association between the two disorders. However, there is scope for diagnostic error as considerable overlap occurs in the symptoms and physical signs of the two conditions. For instance, general slowness, fatigue and apathy, facial hypomimia, a slow monotonous speech, a stooped gait with reduced arm swing, constipation, weight loss, and sleep disturbance occur in both depression and Parkinson's disease. Many patients with Parkinson's disease feel pessimistic and hopeless and became preoccupied with their health. Pilowsky and colleagues (1987) have recently been able to show, using a microcomputer-based approach and a mathematical model of the face to quantify facial expression, that the degree of mouth opening and frequency of smiling is reduced in patients with Parkinson's disease when watching a series of humorous cartoons. They reported a significant correlation between depression scores and frequency of smiling and inner eyebrow separation. They concluded that the patients with Parkinson's disease were unable to react with spontaneous expressive gestures, but that this could not all be attributed to associated depression. Use of surface EMG recordings of facial muscles also holds promise for assessing the degree of depression and movement of the inner eyebrow and corrugator muscle seems particularly important (Schwartz et al., 1978).

There is some evidence to suggest that subtypes of depressive illness exist and psychomotor slowing may be particularly associated with major depressive illness. The constellation of features which make up psychomotor retardation are very similar to those found in some patients with frontal lobe or basal ganglia damage. Attempts have been made to provide research rating scales to assess routinely the degree of motor slowing in affective disorders (see Table 2). It has been reported that individuals with depression and psychomotor retardation have low cerebrospinal fluid, homovanillic acid (HVA) levels, a major catabolite of dopamine (Van Praag et al., 1975) and may improve with L-dopa therapy (Goodwin et al., 1970). Psychomotor retardation might occur in some, but not all patients with Parkinson's disease and so provide a considerable overlap with depressive illness.

Slowness on tests of psychomotor function (Miller, 1975) and impairment on the digit symbol test (Weckowicz, 1972) are shared abnormalities in Parkinson's disease and depression. However, Taylor and colleagues (1986) were unable to find any impairment of short term memory in Parkinson's disease in contrast to a group of endogenously depressed patients. They did, however, find a relative weakness on order-dependent short term memory tests in the patients with Parkinson's disease which they attributed to frontal lobe dysfunction. Patients with Parkinson's disease, on the other hand, appear to have no difficulties in recognition verbal or visual memory (Lees and Smith, 1983; Flowers et al.,1984). Safar and colleagues (1988) have shown, however, that patients with Parkinson's disease may be impaired in their capacity to date past public events despite a preserved ability to recognize the event. The same authors have also shown that this defect is 
only present with short stimulus intervals compared with Alzheimer's disease (Sagar, 1987). These findings would be in keeping with the notion of a slowness of cognitive processing in Parkinson's disease. In contrast, Hart and Quentus (1987) have shown psychomotor slowing on digit symbol and memory scanning, but normal response latency as a function of memory set size in a group of elderly depressive patients suggesting that there may be a normal processing time in depression.

One promising objective measurement for psychomotor retardation is the speech-pause time. This is defined as the silent interval between audible segments of automatic speech defined as counting from 1-10 "taking your own time". In 1976 Szabadi and colleagues studied speech-pause time and phonation time in 4 unipolar depressives and 4 controls. Speech-pause time was prolonged in the patients with depression whereas the phonation time remained constant. Greden (1982) confirmed that depressives had significantly longer speech-pause time than controls and another group of patients with schizophrenia and claimed that a speech-pause time of greater than $2600 \mathrm{msec}$ might be a useful diagnostic test for depression. Hardy and colleagues (1984) have confirmed these findings in 16 patients with depression and were able to show a significant correlation between the speechpause time and Wildlocher scale for retarded depression (see Table 2) but not with the Hamilton rating scale. They were also able to show an improvement in speech-pause time in individual patients following treatment with clomipramine. In fact speech-pause times were first used clinically to assess patients with Parkinson's disease and Mawdsley and Gamsu (1971) found a significant increase in speech-pause time and reduction in phonation time after treatment with L-dopa therapy. The pause time, however, did not differ significantly from normal controls overall although some of the patients had very long pause times pre-treatment, whereas

TABLE 2. Widlocher Retardation Rating Scale (3-point scale)

Motor Items

Gait, stride

Slowness and paucity of movement

Slowness and paucity of head and neck movements

Language and verbal flow

Modulation of the voice

Brevity of responses

Ideational Items

Variety of topics spontaneously approached

Variety of associations to topics proposed by the examiner

Subjective experience of ruminations

Fatiguability

Interest in habitual pastimes

Patient's perception of flow of time

Memory

Concentration 
others as a result of a festinant speech related to their basal ganglia disorder had abnormally short times.

Attempts have also been made to monitor motor activity in depression with telemetry (Kupfer et al., 1974) or with a small activity monitor (Godfrey and Knight, 1984). Royant-Parola et al. (1986) have measured motor activity in 12 middle-aged depressed in-patients using a motor activity monitor worn like a wrist watch on the non-dominant arm. Movements were recorded by a piezo-electric transducer which generated a pulse whenever acceleration exceeded a pre-set threshold. The pulses were counted over a fixed time interval $(15 \mathrm{~min})$. Motor activity was significantly lower than that found in the euthymic state in the same subject. Immobility levels, however, seemed to be a better index of depression especially in the agitated patients, lack of initiation of movement being the main finding.

\section{Neuropsychological impairments in obsessive compulsive disorder and their relation to Parkinson's disease}

Relatively few neuropsychological studies have been carried out in obsessive compulsive disorder, but there is some evidence for abnormalities commonly seen in patients with frontal lobe or basal ganglia damage. Flor-Henry and colleagues (1979) gave 28 psychological test variables based on the Reitan battery to 11 unmedicated patients and found significant abnormalities on the Wepman-Jones aphasia screening test and the Purdue pegboard test and suggested that their overall results would be in keeping with a frontal pattern of cognitive impairment resulting from disturbed inhibition. Insel and colleagues (1983) were unable to confirm these results however in 18 unmedicated patients using the same test battery: 4 patients however, had impairment sufficient to suggest organic deficits and more than half were impaired on the tactual performance test, the latter result in keeping with the results of Flor-Henry. Deficits in logical memory tests in compulsive checkers have also been reported and it has been suggested that these individuals have difficulty recalling details of meaningfully linked sequences either presented in narrative or engaged in personally (Sher et al., 1984).

About $5 \%$ of patients with obsessive compulsive disorders have debilitating slowness in carrying out everyday activities. This may be associated with long periods of immobility, slow motion of the limbs or a breaking up of actions into their component parts which are then carried out serially and extremely slowly. This does not always seem to occur as a consequence of checking rituals or ruminations and is particularly likely to occur in patients with a history of rigidity or introspection.

In collaboration with my colleagues Dr Nigel Hyman and Professor Isaac Marks I have recently had the opportunity to examine 12 young adult in-patients with obsessional compulsive behaviour who had striking slowness. Neurological abnormalities included a delay in initiation of some voluntary movements, a difficulty in switching from one motor programme to another, "stuck-in-set", motor perseveration, difficulty in carrying out two motor acts simultaneously and a general clumsiness and distractibility. 
Some had infrequent blinking and a positive glabellar tap sign, loss of arm swing and two patients had muscular rigidity and progressive difficulty in carrying out sequential movements. In one patient a resting tremor was also present sufficient to make the additional diagnosis of Parkinson's disease and in a further two, multiple tics were present. Many of these patients had difficulty with the Wisconsin card sorting test.

These findings could be interpreted as supporting the idea that obsessional slowness may be the presenting feature of Parkinson's disease or alternatively that some of the problems encountered in this subgroup of patients result from derangement of neuronal systems which are also compromised in Parkinson's disease.

\section{Is there a particular premorbid personality type in Parkinson's disease?}

There is now renewed interest in the idea that Parkinson's disease may be associated with a particular behaviour pattern which deviates from the norm in relatively subtle ways. At least $60 \%$ of nigral compacta nerve cells and $80 \%$ of striatal dopamine has to be lost before the movement disorder appears and it seems probable that the pathological process underlying Parkinson's disease is relatively indolent. This raises the possibility that if a recognizable premorbid personality actually exists then it might occur as a direct result of the underlying neuronal damage.

Mallié (1908) suggested suspiciousness, edginess, tacturnity and melancholia as particular features of the Parkinsonian personality to which Konig (1912) subsequently added hypochondria. Mjones (1949) however, rejected the idea of a particular "paralysis agitans psychopathy" predisposing to the disorder, but noted that after the onset of the illness many had dysphoria and became querulous, exacting, egocentric and excessively irritable; others were noted to have subtle blunting of cognition and attention. Riklan et al. (1959) also denied the existence of a particular Parkinsonian personality type and the idea also proved unacceptable to de Ajuriaguerra (1970) despite his recognition of bradyphrenia as a frequent occurrence in many patients.

Based on carefully studied individual patients however, the psychoanalysts in the first half of this century defined a characteristic personality type (Todes and Lees, 1985). Patients were described as introverted, inflexible, inexpressive and predisposed to depression. Before the onset of their illness they tended to be reliable, industrious, over-conscientious law-abiding citizens with sublimated aggressive and sexual urges and lacking in selfconfidence. Caution however, is necessary in interpreting these observations as similar obsessive and depressive personality traits have been associated with a wide range of other physical disorders including ulcerative colitis (Engel, 1955), cancer, diabetes mellitus and arthritis (Cassileth et al., 1984). However, recent studies have supported the psychoanalysts' views. Poewe and his colleagues (1983) asked patients and spouses to fill out the Gjessen personality inventory retrospectively, addressing their answers to the patient's personality before the onset of their disease. Compared with age- 
matched controls the patients were more inflexible, reliable, subordinate and loyal.

The Parkinson's disease twin study carried out in the U.S.A. has also revealed some interesting differences as early as the first decade between the affected and the non-affected monozygotic twin siblings. From early childhood the affected twin tended to be less dominant and more self-controlled and by the age of 16 was also more nervous. With the onset of Parkinson's disease the affected twin had become less aggressive, quieter and less confident and light-hearted. In the period before the onset of the disease the unaffected twin also smoked significantly more cigarettes than the twin with Parkinson's disease (Ward et al.,1984). This finding is in agreement with several other studies which show that Parkinsonians are twice as likely to have been habitual non-smokers (Kessler and Diamond, 1967; GodwinAusten et al., 1982). It has been suggested that compared to non-smokers adult smokers tend to be more impulsive, arousal seeking, danger loving, risk-taking rebels (Royal College of Physicians), behavioural characteristics more generally associated with extroverts. Cigarette smoking also seems to exert considerable protective effects against ulcerative colitis (Logan et al., 1984), another disorder which has been associated with an inflexible, morose, inward-looking personality. I have collected 25 patients with both ulcerative colitis and Parkinson's disease, only 3 of whom smoked at the time of onset of one of the two disorders and $80 \%$ of whom had never smoked at all. The prevalence of non-smoking for an age-matched social class group in the United Kingdom is about $50 \%$ (Bihari and Lees, 1987). The possibility of a shared distinctive behaviour pattern in the two disorders needs to be further examined in future epidemiological studies.

\section{Conclusion}

Although disorder of movement is responsible for most of the disability experienced by patients with Parkinson's disease, subtle disturbances of behaviour may occur. The neuropsychological abnormalities seen in the malady are similar to those found in retarded depression and obsessional slowness and may antecede the appearance of motor symptoms in a proportion of patients. It remains unclear whether Alzheimer-type dementia occurs more commonly in Parkinson's disease than one would predict by chance, but a protracted confusional state is a common late event in many patients.

\section{References}

Ajuriaguerra J. de (1970) Etude psychopathologique des Parkinsoniens. In "Monoamines noyaux gris centraux et syndrome de Parkinson". (Eds. J. Ajuriaguerra and G. Gauthier Paris, Masson pp 327-351.

Albert, M. L., Feldman, R. G. and Willis, A. L. (1974) The "subcortical dementia" of progressive supranuclear palsy. Journal of Neurology, Neurosurgery and Psychiatry, 37, 121130. 
Barbeau, A. (1973) Biology of the striatum. In "Biology and Brain Dysfunction". (Ed. G. E. Gall Vol. 2 Plenum, New York, pp 333-350.

Bihari, K. and Lees, A. J. (1987) Cigarette smoking, Parkinson's disease and ulcerative colitis. Journal of Neurology, Neurosurgery and Psychiatry, 50, 635

Bowen, F. P., Kamienny, R. S., Burns, M. M. and Yahr, M. D. (1975). Parkinsonism: effects of levodopa treatment on concept formation. Neurology, 25, 701-704.

Brumlik, J. and Boshes, B. (1966) The mechanism of bradykinesia in Parkinsonism. Neurology, 16, 337-344.

Canavan, A. G. M., Passingham, R. E., Marsden, C. D., Quinn, N., Wyke, M. and Polkey, C. E. (1988) The performance on learning tasks of patients in the early stages of Parkinson's disease. Neuropsychologia (in press).

Cassileth, B. R., Lusk, E. J., Strouse, T. B., Miller, D. S., Brown, L. L., Cross, P. A. and Tenaglia, A. N. (1984) Psychosocial status in chronic illness. New England Fournal of Medicine, 311, 506-511.

Engel, G. L. (1955) Studies of ulcerative colitis III. The nature of the psychological processes American Journal of Medicine, 19, 251-256.

Evarts, E. V., Teravainen, H. and Calne, D. B., (1981) Reaction time in Parkinson's disease. Brain, 104, 167-186.

Flor-Henry, P., Yeudall, L. T., Koles, Z. J. and Howarth, B. G. (1979) Neuropsychological and power spectral EEG investigations of the obsessive-compulsive syndrome. Biological Psychiatry, 14, 119-130.

Flowers, K. A., Pearce, I. and Pearce, J. M. S. (1984) Recognition memory in Parkinson's disease. Journal of Neurology, Neurosurgery and Psychiatry, 47, 1174-1181.

Godfrey, H. P. D. and Knight, R. G. (1984) The validity of actometer and speech activity measures in the assessment of depressed patients. British Journal of Psychiatry, 145, 159163.

Godwin-Austen, R. B., Lee, P. N., Marmot, M. G. and Stern, G. M. (1982) Smoking and Parkinson's disease. Fournal of Neurology, Neurosurgery and Psychiatry, 45, 577-581

Goodwin, F. K., Brodie, H. K. H., Murphy, D. L. and Bunney, W. E. (1970) Administration of a peripheral dopa decarboxylase inhibitor with L-dopa to depressed patients. Lancet, $\mathbf{i}$, 908-911.

Gotham, A-M., Brown, R. G. and Marsden, G. D. (1988) "Frontal" cognitive function in patients with Parkinson's disease "on" and "off' levodopa. Brain (in press).

Greden, J. F., (1982) Biological markers of melancholia and reclassification of depressive disorders. Encephale, 8, 193-202.

Hansch, E. C., Syndulko, K., Cohen, S. N., Goldberg, Z. I., Potuin, A. R. and Tourtellotte, W. W. (1982) Cognition in Parkinson's disease: an event-related potential perspective. ii, 599-607.

Hardy, P., Jouvent, R. and Widlocher, D. (1984) Speech pause time and the retardation rating scale for depression. Fournal of Affective Disorders, 6, 123-127.

Hart, R. P. and Kwentus, J. A. (1987) Psychomotor slowing and subcortical type dysfunction in depression. Journal of Neurology, Neurosurgery and Psychiatry, 50, 1263-1266.

Insel, T. R., Donnelly, E. F., Lalakea, M. L., Alterman, I. S. and Murphy, D. L. (1983) Neurological and neuropsychological studies of patients with obsessional-compulsive disorder. Biological Psychiatry, 18, 741-751.

Jankovic, J., Kirkpatrick, J. B., Blomquist, K. A., Langlais, P. J. and Bird, E. D. (1985) Lateonset Hallervorden-Spatz disease presenting as familial Parkinsonism Neurology, 35, 227234.

Katsikitis, M. and Pilowsky, I. (1988) A study of facial expression in Parkinson's disease using a novel microcomputer-based method. Fournal of Neurology, Neurosurgery and Psychiatry, (in press).

Kessler, I. I. and Diamond, K. L. (1967) Epidemiological studies of Parkinson's disease. 1. Smoking and Parkinson's disease. American Journal of Epidemiology, 94, 16-25.

Konig, H. (1912) Zur psychopathologie der paralysis agitans. Archives of Psychiatry, 50, 285.

Kupfer, D. J., Weiss, B. L., Foster, F. G., Detre, T. P., Delgado, J. and McPartland, R. (1974) Psychomotor activity in affective states. Archives of General Psychiatry, 30, 765-768. 
Lees, A. J. and Smith, E. (1983) Cognitive deficits in the early stages of Parkinson's disease. Brain, 106, 257-270.

Logan, R. F. A., Edmond, M., Somerville, K. W. and Langman, M. J. S. (xxxx) Smoking ulcerative colitis. British Medical Fournal, 288, 751-753.

Mallié A-H. (1908) Les troubles psychiques chez les Parkinsoniens. Thèse de Bordeaux.

Rogers, D., Lees, A. J., Smith, E., Trimble, M. and Stern, G. M. (1987) Bradyphrenia in Parkinson's disease and psychomotor retardation in depressive illness: an experimental study. Brain, 110, 761-776.

Royal College of Physicians (1977) "Smoking and Health" London. Pitman Medical.

Royant-Parola, S., Borbely, A. A., Tobler, I., Benoit, O. and Widlocher, D. (1986) Monitoring of long-term motor activity in depressed patients. British fournal of Psychiatry, 149, 288-293.

Sagar, H. J. (1987) Clinical similarities and differences between Alzheimer's disease and Parkinson's disease. Journal of Neural Transmission suppl. 24, 87-89.

Sagar, H. J., Cohen, N. J., Sullivan E. V., Corkin, S. and Growdon, J. H. (1988) Remote memory function in Alzheimer's disease and Parkinson's disease. Brain (in press).

Sandson, J. and Albert, M. (1987) Perseveration in behavioural neurology. Neurology, 37, 1736-1741.

Santamaria, J., 'Tolosa, E. S., Valles, A., Bayes, A., Blesa, R. and Masana, J. (1987) Mental depression in untreated Parkinson's disease of recent onset. In "Advances in Neurology" vol. 45. (Eds. M. D. Yahr and K. J. Bergmann). Raven Press, New York, pp 443-445.

Schwartz, G. E., Fair, P. L., Mandell, M. R., Salt, P., Mieske, M. and Klerman, G. L. (1978) Facial electromyography in the assessment of improvement in depression. Psychosomatic Medicine, 40, 355-360.

Shaw, K. M., Lees, A. J. and Stern, G. M. (1980) The impact of treatment with levodopa on Parkinson's disease. Quarterly Fournal of Medicine, 49, 283-293.

Sher, K. J., Mann, B. and Frost, R. D. (1984) Cognitive dysfunction in compulsive checkers: further explorations. Behavioural Research Therapy, 22, 493-502.

Starkstein, S., Leiguarda, R., Gershanik, O. and Berthier, M. (1987) Neuropsychological disturbances in hemi-Parkinson's disease. Neurology, 37, 1762-1764.

Szabadi, E., Bradshaw, C. M. and Besson, J. A. O. (1976) Elongation of pause-time in speech: a simple objective measure of motor retardation in depression. British fournal of Psychiatry, 129, 592-597.

Taylor, A. E., Saint-Cyr, J. A. and Lang, A. E. (1986a) Frontal lobe dysfunction in Parkinson's disease Brain, 109, 845-883.

Taylor, A. E., Saint-Cyr, J. A., Lang, A. E. and Kenny, F. 'T. (1986b) Parkinson's disease and depression. A critical re-evaluation. Brain, 109, 279292.

Todes, C. J. and Lees, A. J. (1985) The pre-morbid personality of patients with Parkinson's disease. Journal of Neurology, Neurosurgery and Psychiatry, 48, 97-100.

Van Praag, H. M., Korf, J., Laake, J. P. W. F. and Schut, T. (1975) Dopamine metabolism in depressions, psychosies and Parkinson's disease. The problem of specificity of biological variables in behavioural disorders. Psychological Medicine, 5, 138-146.

Ward, C. D., Duvoisin, R. C. and Ince, S. E. (1984) Parkinson's disease in twins. In "Advances in Neurology" (Eds. R. G. Hassler and J. F. Christ) vol. 40 Raven Press, New York, pp 341-344.

Weckowitz, T. E., Nutter, R. W., Cruise, D. G. and Yonge, K. A. (1972) Speed in test performance in relation to depressive illness and age. Canadian Psychiatric Association Fournal, 17 suppl.2, 241-250.

Wilson, R. S., Kasniak, A. W., Klawans, H. L. and Garron, D. C. (1980) High speed memory scanning in Parkinsonism. Cortex, 16, 67-72.

Wilson S. A. K. (1955) In "Neurology" 2nd Ed. Butterworth \& Co., London Vol. 2 p 933.

Worster-Drought, C. and Hardcastle, D. N. (1924) A contribution to the psychopathology of residual encephalitis lethargica. Fournal of Neurology of Psychopathology, 5, 146-150. 


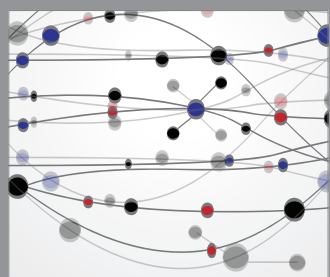

The Scientific World Journal
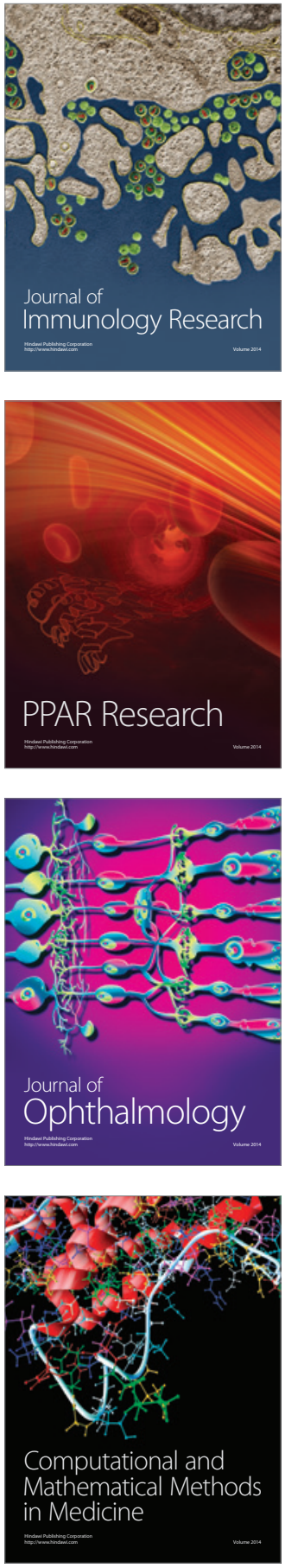

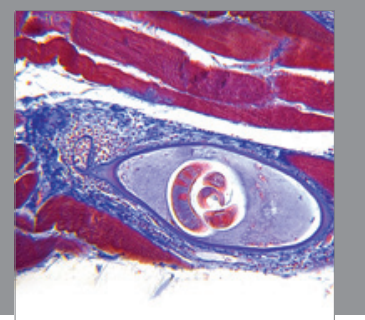

Gastroenterology

Research and Practice
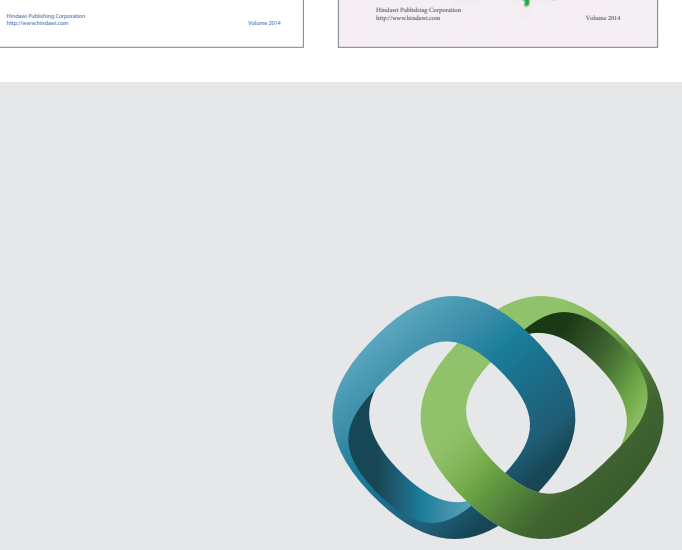

\section{Hindawi}

Submit your manuscripts at

http://www.hindawi.com
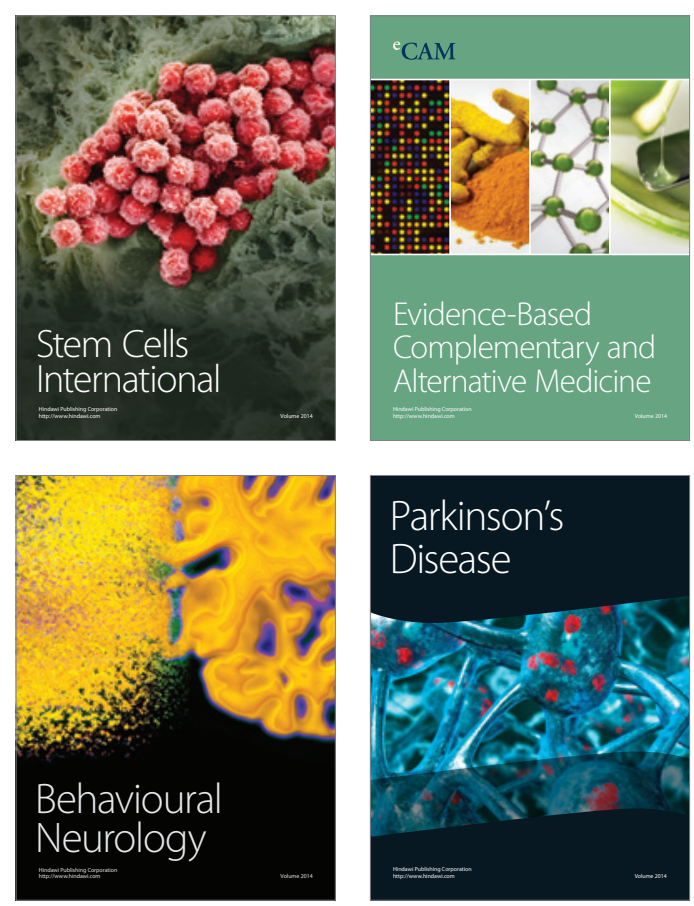

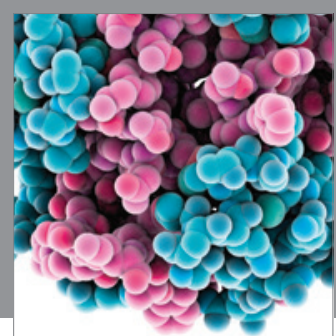

Journal of
Diabetes Research

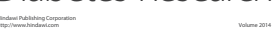

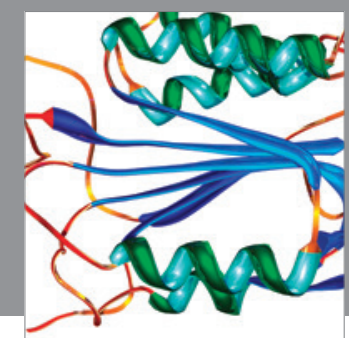

Disease Markers
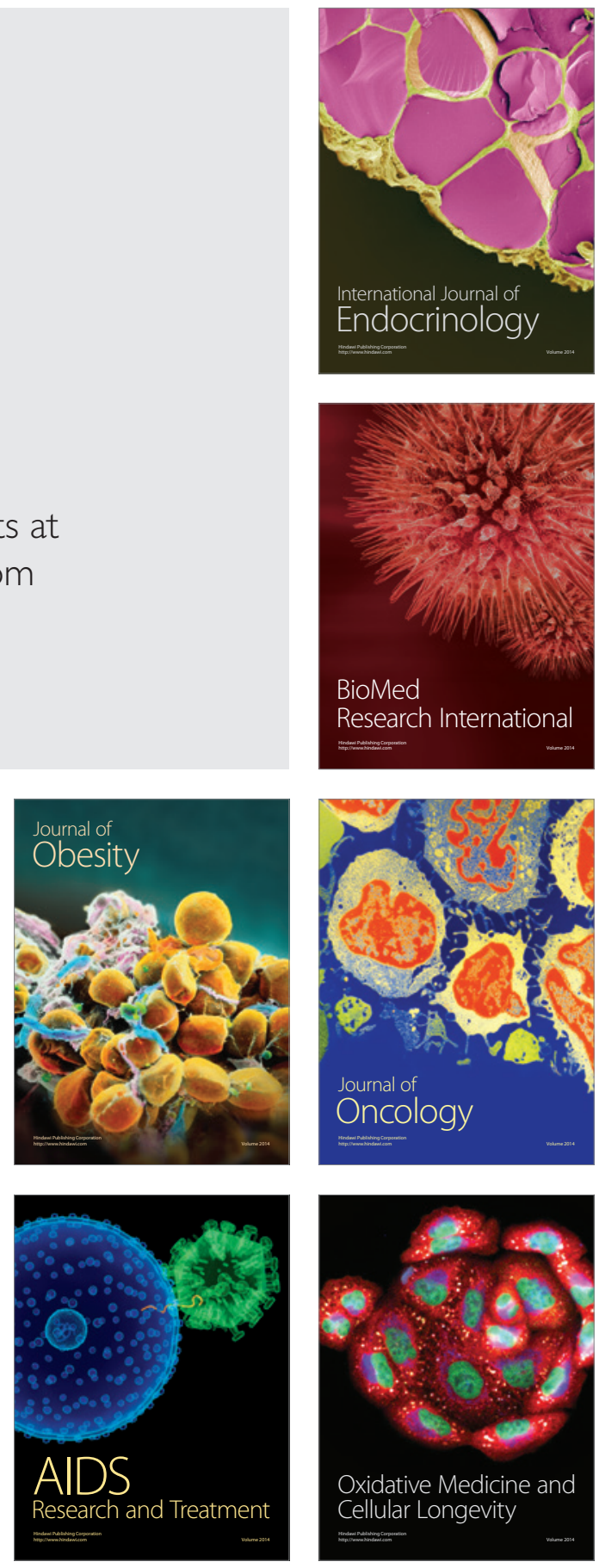